\section{Case Reports in Ophthalmology}

Case Rep Ophthalmol 2020;11:217-221

DOI: 10.1159/000507608

Published online: June 15, 2020

(C) 2020 The Author(s)

Published by S. Karger AG, Basel

www.karger.com/cop

This article is licensed under the Creative Commons Attribution-NonCommercial 4.0 International License (CC BY-NC) (http://www.karger.com/Services/OpenAccessLicense). Usage and distribution for commercial purposes requires written permission.

\title{
Migration of Silicone Oil into the Orbit and Eyelid as a Cyst
}

\author{
Mohammad Sharifi Mohammad Reza Ansari Astaneh \\ Eye Research Center, Mashhad University of Medical Science, Mashhad, Iran
}

\section{Keywords}

Silicone oil · Orbit · Eyelid · Migration

\begin{abstract}
A 7-year-old female presented with left upper eyelid swelling following pars plana deep vitrectomy and silicone oil injection 1 year before admission. The left upper eyelid had mechanical ptosis and on palpation there was a lobulated mobile mass in the lateral portion of eyelid. Computed topography scan showed multiple isodense masses with silicone oil in vitreous in the eyelid and orbit; histopathology after excisional biopsy proved the silicone oil migration. Silicone oil migration followed by vitrectomy may be due to leakage from the site of initial wounds or vitrectomy ports. It is important to suspect extraocular silicone oil migration in patients who presented with eyelid mass-like lesions with a history of silicone oil injection following pars plana deep vitrectomy.

(C) 2020 The Author(s) Published by S. Karger AG, Basel
\end{abstract}

\section{Introduction}

Silicone oil is commonly used in vitreoretinal surgeries as an internal tamponade. These materials are inert and nontoxic. There are several reports on the migration of intraocular silicone oil into the subconjunctival space $[1,2]$, orbit $[3,4]$, upper eyelid [5-7] and central nervous system [8]. 


\section{Case Reports in Ophthalmology}

The current paper reports the migration of silicone oil into the upper eyelid in a patient who underwent pars plana deep vitrectomy due to perforating eye trauma.

\section{Case Report}

A 7-year-old female was referred to the clinic due to left upper eyelid swelling and masslike lesion after pars plana deep vitrectomy and silicone oil injection due to penetrating eye surgery 1 year before admission.

On ophthalmologic examination, left eye visual acuity was counting fingers at $20 \mathrm{~cm}$; the retina was attached, and the eye was filled with silicone oil.

On external examination, the left upper eyelid had mechanical ptosis. On palpation, there was a mobile mass in the lateral portion of the left upper eyelid.

Orbital computed tomography scan was performed and showed multiple well-defined masses, isodense with silicone oil in vitreous, in the left upper eyelid. The lateral mass was larger than the medial ones and seemed lobulated. There were also 2 abnormal isodense masses with silicone oil in the intraconal space of the left orbit (Fig. 1).

It was decided to perform a transcutaneous excisional biopsy for eyelid masses. Eyelid biopsy showed cystic lesions, which were solid and translucent (Fig. 2). The largest one was $10 \times 18 \mathrm{~mm}$ in diameter. Complete excision of globules was done, and the skin was sutured by nonabsorbable suture.

Histopathology showed foreign-body reactions to the cysts of silicone oil (Fig. 3). The patient was followed up after 1 week for suture removal; no sign of recurrence was observed, and the mechanical ptosis was significantly improved.

\section{Discussion}

Silicone oil is used to treat complex vitreoretinal diseases such as proliferative diabetic retinopathy, retinal detachment, and severe eye trauma [9-12].

Intraocular silicone oil is associated with a number of complications such as glaucoma, cataract, subretinal migration of silicone oil, and proliferation of epiretinal and subretinal fibrosis, keratopathy, and in rare situations the migration of silicone oil into the orbit. Migration of silicone oil into the orbit and upper eyelid was also reported after retina surgery following pars plana vitrectomy due to proliferative diabetic retinopathy [6], endogenous endophthalmitis [13] and penetrating eye trauma [14].

It was supposed that silicone oil might leak though the pars plana vitrectomy port, posterior scleral, and corneal wound, during or after the surgery, which should be aggravated by increased intraocular pressure postoperatively.

Dehiscence of the levator aponeurosis was not observed in the current case, but it was reported in previous case reports [14].

It is recommended to remove intraocular silicone oil as soon as possible and to follow-up the patient who retained silicone oil for an extended period of time more frequently.

The extraocular silicone oil was manifested as a mass with mechanical ptosis in the current case; hence, it is recommended to be suspicious of silicone oil migration in patients with a history of vitreoretinal surgery and silicone oil injection if the patient complains of eyelid swelling, ptosis, or mass postoperatively. 


\section{Case Reports in Ophthalmology}

Acknowledgement

We would like to acknowledge everyone who played a role in the manuscript, especially my colleagues in the Khatam Eye Hospital.

\section{Statement of Ethics}

The manuscript was approved by the ethics committee of Mashhad University of Medical Sciences.

\section{Disclosure Statement}

The authors declare that they have no conflicts of interest.

\section{Funding Source}

The authors received funding from the Eye Research Center, Mashhad University of Medical Sciences, Mashhad, Iran.

\section{References}

1 Chan CK, Tarasewicz DG, Lin SG. Subconjunctival migration of silicone oil through a Baerveldt pars plana glaucoma implant. Br J Ophthalmol. 2005 Feb;89(2):240-1.

2 Friberg TR, Fanous MM. Migration of intravitreal silicone oil through a Baerveldt tube into the subconjunctival space. Semin Ophthalmol. 2004 Sep-Dec;19(3-4):107-8.

3 Nazemi PP, Chong LP, Varma R, Burnstine MA. Migration of intraocular silicone oil into the subconjunctival space and orbit through an Ahmed glaucoma valve. Am J Ophthalmol. 2001 Dec;132(6):929-31.

4 Wenkel H, Naumann GO. [Retrolaminar infiltration of optic nerve with intraocular tamponade following silicone oil instillation]. Klin Monatsbl Augenheilkd. 1999 Feb;214(2):120-2.

5 Dehghani A, Rezaei L, Tavallali A, Dastborhan Z. Upper Eyelid Silicone Oil Migration after Sutureless 23gauge Vitrectomy. Adv Biomed Res. 2017 May;6(1):58.

6 Deguchi Y, Maeno T, Hori Y, Hiruta N, Sasai D, Sato Y. Migration of intraocular silicone oil from the vitreous cavity into the upper eyelid causing ptosis. Case Rep Ophthalmol. 2014 Jul;5(2):226-30.

7 Quintyn JC, Genevois 0, Ranty ML, Retout A. Silicone oil migration in the eyelid after vitrectomy for retinal detachment. Am J Ophthalmol. 2003 Sep;136(3):540-2.

8 Filippidis AS, Conroy TJ, Maragkos GA, Holsapple JW, Davies KG. Intraocular Silicone Oil Migration into the Ventricles Resembling Intraventricular Hemorrhage: Case Report and Review of the Literature. World Neurosurg. 2017 Jun;102:695.e7-10.

9 Morphis G, Irigoyen C, Eleuteri A, Stappler T, Pearce I, Heimann H. Retrospective review of 50 eyes with long-term silicone oil tamponade for more than 12 months. Graefes Arch Clin Exp Ophthalmol. 2012 May;250(5):645-52.

10 Thomas BJ, Yonekawa Y, Ruby AJ, Capone A Jr. Aggressive Surgical Therapy With Early Vitrectomy, Panretinal Photocoagulation, and Silicone Oil Tamponade for Streptococcus mitis Endophthalmitis. Ophthalmic Surg Lasers Imaging Retina. 2015 Sep;46(8):893-5.

11 Ghasemi Falavarjani K, Modarres M, Hadavandkhani A, Karimi Moghaddam A. Intra-silicone oil injection of methotrexate at the end of vitrectomy for advanced proliferative diabetic retinopathy. Eye (Lond). 2015 Sep;29(9):1199-203.

12 Dikopf MS, Patel KH, Setlur VJ, Lim JI. Surgical outcomes of 25-gauge pars plana vitrectomy for diabetic tractional retinal detachment. Eye (Lond). 2015 Sep;29(9):1213-9. 


\section{Case Reports in Ophthalmology}

\begin{tabular}{l|l}
\hline DOI: $10.1159 / 000507608$ & ○ 2020 The Author(s). Published by S. Karger AG, Basel
\end{tabular}
www.karger.com/cop

Sharifi and Ansari Astaneh: Migration of Silicone Oil into the Orbit and Eyelid

13 Lee JH, Kim YD, Woo KI, Kong M. Subconjunctival and orbital silicone oil granuloma (siliconoma) complicating intravitreal silicone oil tamponade. Case Rep Ophthalmol Med. 2014;2014:686973.

14 Mustafa TA, Al-Zuoby KM, Alawneh AM. Mechanical blepharoptosis and eyelid swelling caused by silicone Oil. J Optom. 2009;2(1):27-8.

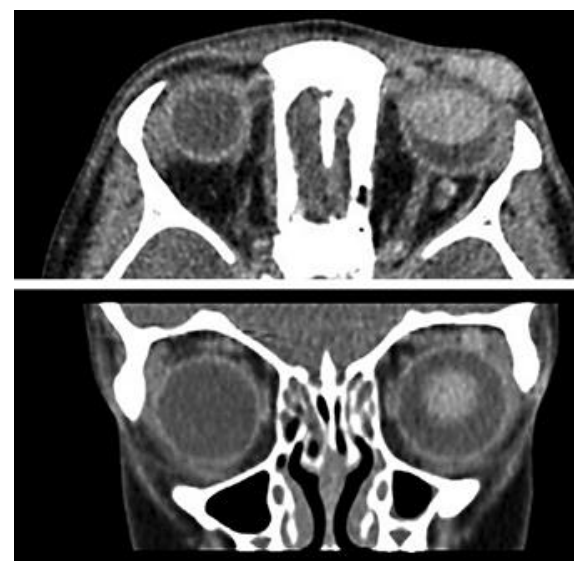

Fig. 1. Top: the orbital computed tomography scan in the axial sections shows multiple well-defined isodense masses with silicone oil in vitreous, in the upper eyelid and intraconal spaces of the left eye. Down: another isodense mass with silicone oil is presented in the coronal plane of the left eye between the superior and lateral rectus muscle. 


\section{Case Reports in Ophthalmology}

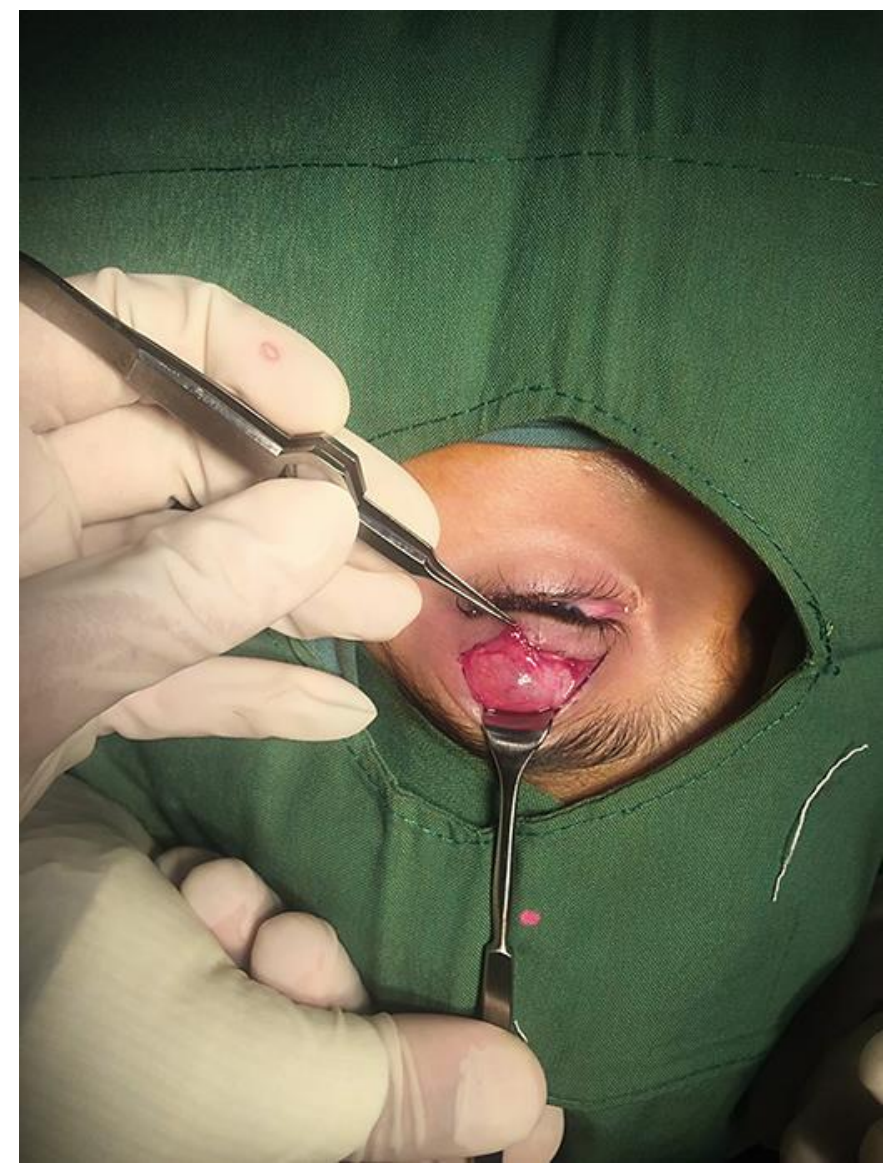

Fig. 2. Transcutaneous excisional biopsy was performed for eyelid masses. The silicone oil globules were solid and translucent.

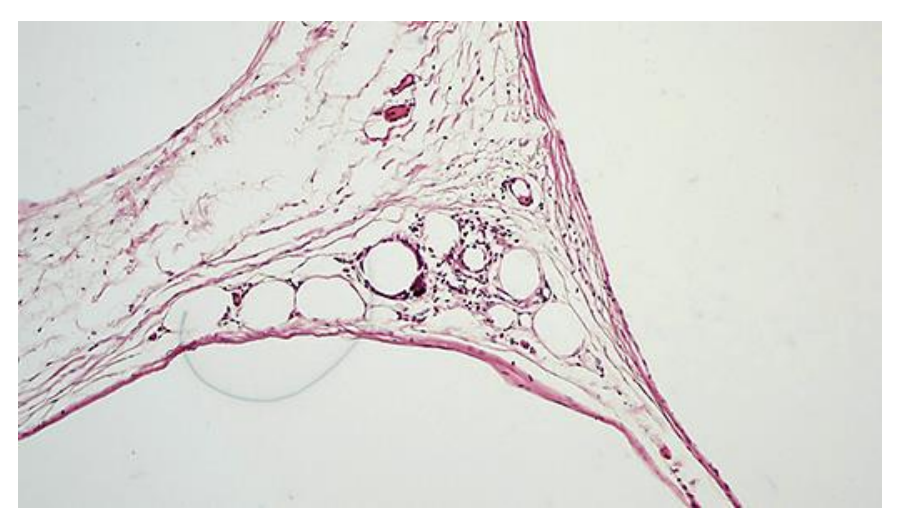

Fig. 3. Cystic spaces of different sizes with delicate fibrous walls and no epithelial linings were discovered on histologic examination. 